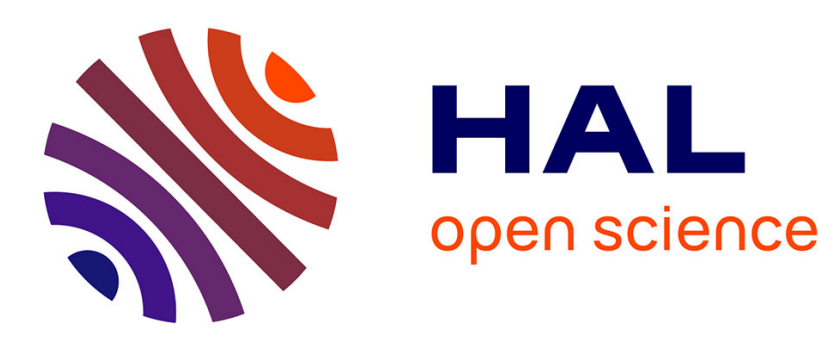

\title{
Well GeHP detector calibration for environmental measurements using reference materials
}

\author{
A Tedjani, C Mavon, A Belafrites, D Degrelle, D Boumala, D Rius, J.-E
}

Groetz

\section{To cite this version:}

A Tedjani, C Mavon, A Belafrites, D Degrelle, D Boumala, et al.. Well GeHP detector calibration for environmental measurements using reference materials. Nuclear Instruments and Methods in Physics Research Section A: Accelerators, Spectrometers, Detectors and Associated Equipment, 2016, 838, pp.12-17. 10.1016/j.nima.2016.09.022 . hal-01367643

\section{HAL Id: hal-01367643 \\ https://hal.science/hal-01367643}

Submitted on 16 Sep 2016

HAL is a multi-disciplinary open access archive for the deposit and dissemination of scientific research documents, whether they are published or not. The documents may come from teaching and research institutions in France or abroad, or from public or private research centers.
L'archive ouverte pluridisciplinaire HAL, est destinée au dépôt et à la diffusion de documents scientifiques de niveau recherche, publiés ou non, émanant des établissements d'enseignement et de recherche français ou étrangers, des laboratoires publics ou privés. 


\title{
Well GeHP detector calibration for environmental measurements using reference materials
}

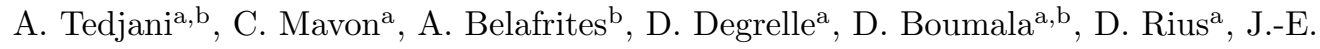 \\ Groetz $^{\mathrm{a}, *}$ \\ ${ }^{a}$ Laboratoire Chrono-Environnement, UMR CNRS 6249, Université de Bourgogne Franche-Comté, \\ F-25030 Besançon, France \\ ${ }^{b}$ Laboratoire de Physique des Rayonnements et Applications, Université de Jijel, B.P. 98, Oueled \\ Aissa, Jijel 18000, Algeria
}

\begin{abstract}
A well-type detector installed in the Modane underground Laboratory (LSM) can combine both low background and high detection efficiency and it is well suited for the analysis of small amounts of environmental samples. Reference materials such as IAEA447 (moss-soil), IAEA-RG-Th1 and IAEA-RG-U1 were used for the detector calibration, owing to a chemical composition close to those of the environmental samples. Nevertheless, the matrix effects and the true coincidence summing effects must be corrected from the full energy peak efficiency (FEPE). The FEPE was performed for a wide range of energy by a semi-empirical method using Monte Carlo simulation (MCNP6), intended for environmental measurements such as lake sediments dating. In the well geometry, the true coincidence summing effects could be very important and correction factors have been computed in three different ways.
\end{abstract}

Keywords: Well-type detector; Full energy peak efficiency; True coincidence summing; MCNP6; Efficiency correction

\section{Introduction}

2 The detector full energy peak efficiency (FEPE) calibration is always required to 3 reach accurate measurements and still represents a subject of considerable interest for

\footnotetext{
*Corresponding author Tel. : + 33381666507 ; fax: + 33381666522

Email address: jegroetz@univ-fcomte.fr (J.-E. Groetz)
} 
4 the gamma spectrometry [1, 2, 4-10]. In this work, the measurements were carried 5 out with a well high-purity germanium (HPGe) detector, situated in the underground 6 Laboratory of Modane (LSM, located along the Frejus Tunnel Rood in Savoy) where the reachable sensitivity depends on the ultra-low background. The FEPE calibration of the 8 well detector $[1,2,4,7,8,10]$ is required for environmental measurements, mainly the 9 determination of fallout radionuclides in lake sediments such as ${ }^{210} \mathrm{~Pb}$ (half-life 22.3 years) ${ }^{10}$ and ${ }^{137} \mathrm{Cs}$ (half-life 30.05 years) for dating methods. To determine the FEPE function, 11 standard calibration sources, with the same size and composition as the samples, should 12 be used to have the same matrix effects (concerning mainly the auto-absorption due to the density and the chemical composition) that will be corrected. Reference materials such as IAEA-447 (moss-soil), RG-Th1 (thorium ore) and RG-U1 (uranium ore) were used in the calibration process. Therefore, an important correction applied in close 16 measurements for this kind of detector, is related to the true coincidence summing effect 17 (TCS). TCS occurs when two (or more) emitted gamma or X-rays from a nucleus are 18 simultaneously detected within the resolving time of the gamma spectrometer system. 19 The magnitude of this effect depends on the detector efficiency (including the specific 20 source-detector geometry for a well detector) and the decay-scheme parameters. For 21 the concerned nuclei, TCS usually results in lower full-energy peak areas. In order to 22 compensate this loss of counts, a suitable correction must be performed. TCS correction 23 factors were computed for ${ }^{214} \mathrm{Bi}$ (half-life $20 \mathrm{~min}$ ), using secular equilibrium between ${ }_{24}{ }^{226} \mathrm{Ra}$ (half-life 1600 years) and their progenies, especially ${ }^{214} \mathrm{Bi}$ and ${ }^{214} \mathrm{~Pb}$ with their 25 free lines of TCS effect at $295.22 \mathrm{keV}$ and $351.93 \mathrm{keV}$. A simple way to get the correction 26 factor is to compare their activities, for example with the Genie 2000 software [11], which 27 should be equal.

A comprehensive study of the efficiency calculation and calibration verification of 29 the well spectrometer was performed by a semi-empirical method using Monte-Carlo 30 simulation, where the key element for calibration is the accurate knowledge of the physical 31 and geometrical characteristics of the whole detector, such as length and diameter of the 32 Ge crystal, thickness of the dead layer and more generally features of other components 3з (endcap, crystal holder, insulators, ....). A detector model was created for the efficiency 34 calculation, using the MCNP6 code [12]. This allowed to achieve a better accuracy for the 
35 activity measurements of samples with unusual shapes, where experimental calibration

36 with standard sources appears to be difficult.

\section{2. Materials and methods}

38 2.1. Well HPGe detector

The spectrometer used in this work is a Canberra High-Purity Germanium (HPGe)

40 well detector, model GCW4021 under a serial number b07035, with a relative efficiency

${ }_{41}$ of $40 \%$, an active volume of $238 \mathrm{~cm}^{3}$ and a nominal FWHM of $1.27 \mathrm{keV}$ at $122 \mathrm{keV}\left({ }^{57} \mathrm{Co}\right)$

${ }^{42}$ and $2.03 \mathrm{keV}$ at $1.33 \mathrm{MeV}\left({ }^{60} \mathrm{Co}\right)$. These features were supplied by the manufacturer. It

43 works coupled to a DSA-1000 Canberra multichannel analyser and provides a maximum

44 efficiency for small samples, because the sample is virtually surrounded by the active

45 detector material.

46 The Canberra well detector is fabricated with a blind hole rather than a through 47 hole, leaving at least $15 \mathrm{~mm}$ of active detector thickness at the bottom of the well. The

48 counting geometry therefore approaches $4 \pi \mathrm{sr}$.

49 The well insert in the end-cap is made of low background (LB) aluminium with a side50 wall thickness of $1.5 \mathrm{~mm}$ and a $1 \mathrm{~mm}$ thick bottom. The ion boron implanted contact on 51 the detector element is negligibly thin compared to $0.5 \mathrm{~mm}$ of aluminium, so this kind

52 of detector has intrinsically a good response at low energy, down to $20 \mathrm{keV}$ [13]. The

53 detector is shielded with a foil of electrolytic copper (3 mm thick) and lead (12 cm of 54 low activity lead $<50 \mathrm{~Bq} \mathrm{~kg}^{-1}$ and $3 \mathrm{~cm}$ of very low activity lead $<10 \mathrm{~Bq} \mathrm{~kg}^{-1}$ ).

${ }_{55}$ A completed description of the equivalent detector model is represented in Fig. 1, 56 where the dimensions are taken from the Canberra handbook.

${ }_{57}$ Table 1 summarizes the values specified by Canberra for the geometric features of the 58 well detector shown in Fig. 1.

59 2.2. Monte-Carlo simulations

The characterisation of the detector usually combines experimental measurements and Monte-Carlo simulations to calculate with accuracy the detector efficiency.

An initial model of the detector was performed by using the nominal dimensions and features provided by the manufacturer and then was implemented in the Monte-Carlo 


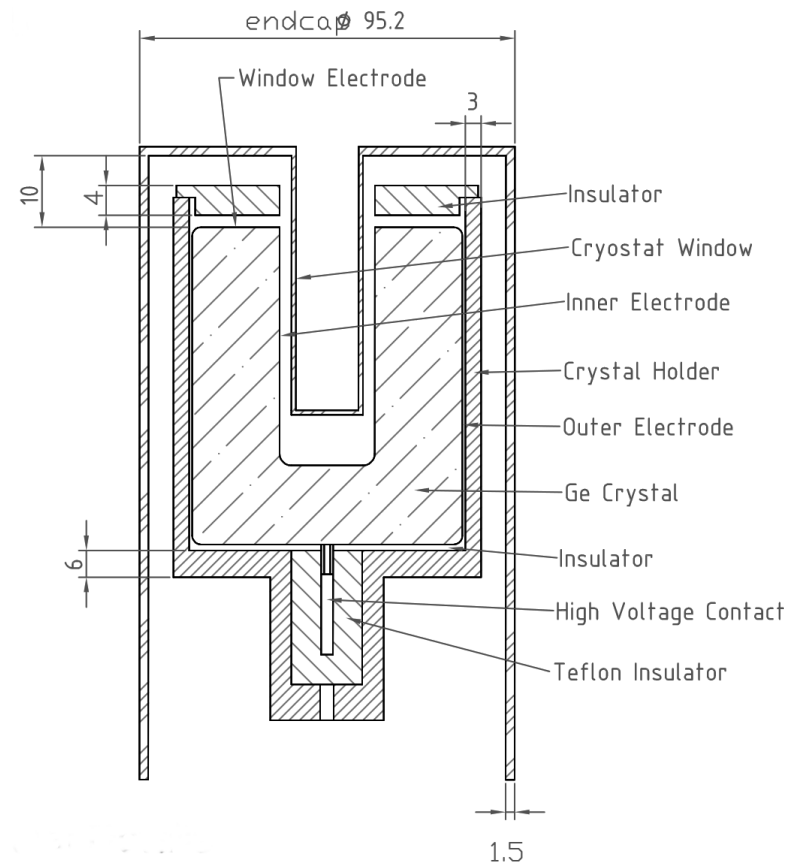

Figure 1: Well detector longitudinal section.

\begin{tabular}{lc}
\hline Parameters & Value $(\mathrm{mm})$ \\
\hline Outer electrode thickness & 0.9 \\
\hline Inner electrode thickness & $0.3 \times 10^{-3}$ \\
\hline Window electrode thickness & 0.9 \\
\hline Cristal diameter & 68 \\
\hline Cristal length & 68 \\
\hline Core hole diameter & 17 \\
\hline Endcap hole & 35 \\
\hline Core hole depth & LBameter $11 \mathrm{~mm}$ and depth $40 \mathrm{~mm}$ \\
\hline Cryostat window material & LB aluminium $1.5 \mathrm{~mm}$ thick \\
\hline Endcap material & LB copper \\
\hline Crystal holder &
\end{tabular}

Table 1: Well detector parameters. 
code MCNP6. This detector model must be checked by comparing the efficiency curve

${ }_{65}$ provided by MCNP6 with the experimental one obtained for source-detector geometry

66 and reference materials in a wide energy range. The detector model should be approved if

67 the calculated efficiencies are in a good agreement with the experimental values according

${ }_{68}$ to a level of acceptable uncertainty. Note that MCNP6 intrinsically does not take into

69 account the TCS effect.

Fig. 2 shows the detector model obtained by MCNP6. The detector resolution was 71 taking into account through the GEB (Gaussian Energy Broadening) card.

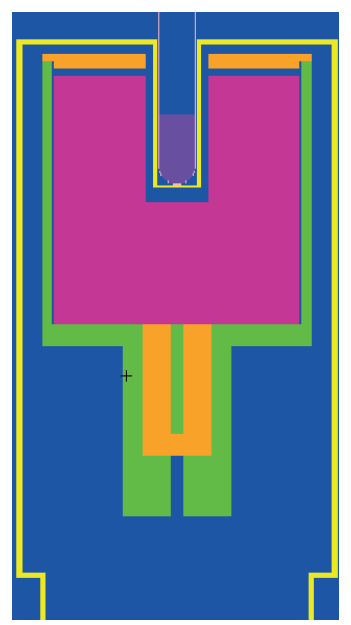

Figure 2: 2-D representation of the well detector MCNP 3-D model.

\subsection{IAEA447 Standard}

The experimental efficiency calibration was carried out in the $46.54-2614.51 \mathrm{keV}$ energy range using the IAEA-447 standard (moss-soil). The milled material was sieved to obtain a maximum particle size distribution of $150 \mu \mathrm{m}$. The material density was measured in 5 test portions and found to be $1.03 \pm 0.05 \mathrm{~g} \mathrm{~cm}^{-3}$ [14].

The certified values used to evaluate the activities of radionuclides were established on the basis of results reported by the IAEA Terrestrial Environment Laboratory in Seibersdorf, Austria [14].

Radionuclides from this sample and their activities estimated at the date of our experiment are represented in Table 2 . 


\begin{tabular}{lcc}
\hline Radionuclides & $\begin{array}{c}\text { Certified Values } \\
\left(\mathrm{Bq} \mathrm{kg}^{-1}\right)\end{array}$ & $\begin{array}{c}\text { Uncertainty } \\
\left(\mathrm{Bq} \mathrm{kg}^{-1}\right)\end{array}$ \\
\hline${ }^{137} \mathrm{Cs}$ & 383.46 & 10.00 \\
${ }^{210} \mathrm{~Pb}$ & 378.65 & $0.02 \times 10^{3}$ \\
${ }^{210} \mathrm{Po}$ & 378.65 & 10.00 \\
${ }^{212} \mathrm{~Pb}$ & 8.28 & 1.50 \\
${ }^{226} \mathrm{Ra}$ & 25,05 & 2.00 \\
${ }^{228} \mathrm{Ac}$ & 15,49 & 2.00 \\
${ }^{234} \mathrm{U}$ & 21.80 & 0.80 \\
${ }^{238} \mathrm{U}$ & 22.20 & 0.80 \\
${ }^{238} \mathrm{Pu}$ & 0.15 & 0.02 \\
${ }^{239-240} \mathrm{Pu}$ & 5.30 & 0.20 \\
${ }^{40} \mathrm{~K}$ & 550 & $0.02 \times 10^{3}$ \\
${ }^{90} \mathrm{Sr}$ & 4.50 & 0.30 \\
${ }^{232} \mathrm{Th}$ & 37.30 & 20 \\
${ }^{241} \mathrm{Am}$ & 2.20 & 0.20 \\
${ }^{241} \mathrm{Pu}$ & 6.45 & 1.00 \\
\hline
\end{tabular}

Table 2: Estimated values of activities by Darwin software from IAEA-447 certified ones.

82 2.4. IAEA-RGU-1 and IAEA-RGTh-1 Standards

83 Both IAEA-RGU-1 and IAEA-RGTh-1 reference materials were prepared, on be-

84 half of the International Atomic Energy Agency by the Canada Centre for Mineral and

85 Energy Technology, by dilution of respectively a uranium ore BL-5 (7.09\% U) and a

${ }_{86}$ thorium ore OKA-2 $(2.89 \% \mathrm{Th}, 219 \mu \mathrm{g} \mathrm{U} / \mathrm{g})$ with floated silica powder of similar grain

${ }_{87}$ size distribution. BL-5 has been certified for uranium, ${ }^{226} \mathrm{Ra}$ and ${ }^{210} \mathrm{~Pb}$, confirming that

88 it is in radioactive equilibrium. The agreement between radiometric and chemical mea-

89 surements of thorium and uranium in OKA-2 shows that both series are in radioactive

90 equilibrium [15].

91 The activities of radionuclides from IAEA-RG-Th1 and IAEA-RG-U1 are shown in 92 Table 3 . 


\begin{tabular}{cc|cc}
\hline \multicolumn{2}{c|}{ IAEA-RG-Th1 } & \multicolumn{2}{c}{ IAEA-RG-U1 } \\
Radionuclide & Activity $\left(\mathrm{Bq} \mathrm{kg}^{-1}\right)$ & Radionuclide & Activity $\left(\mathrm{Bq} \mathrm{kg}^{-1}\right)$ \\
\hline${ }^{232} \mathrm{Th}$ & 3250 & ${ }^{232} \mathrm{Th}$ & $<4$ \\
${ }^{235} \mathrm{U}$ & 3.6 & ${ }^{235} \mathrm{U}$ & 238 \\
${ }^{238} \mathrm{U}$ & 78 & ${ }^{238} \mathrm{U}$ & 4940 \\
${ }^{40} \mathrm{~K}$ & 6.3 & ${ }^{40} \mathrm{~K}$ & $<0.68$ \\
\hline
\end{tabular}

Table 3: IAEA-RG-Th1 (thorium ore) and IAEA-RG-U1 (uranium ore) certified values of activities.

\subsection{Experimental}

All measurements in this work were performed at the LSM. The laboratory is shielded from cosmic radiation by $1700 \mathrm{~m}$ of rocks, equivalent to $4400 \mathrm{~m}$ of water, and an air flushing without radon (generated from the radon trapping facility at the LSM) is done into the measurement cell, inside the lead shielding. Thus the background rate between $20 \mathrm{keV}$ and $2 \mathrm{MeV}$ is of 23 counts $\mathrm{h}^{-1}$. Three reference materials cited above were used in containers with the following features:

- IAEA-447 in a PE tube of $28 \mathrm{~mm}$ of height and $1.341 \mathrm{~g}$ of weight;

- IAEA-RG-Th1 in a PE tube of $28 \mathrm{~mm}$ and $1.4 \mathrm{~g}$;

- IAEA-RG-U1 in a PE tube of $28 \mathrm{~mm}$ and $1.849 \mathrm{~g}$.

The reference material samples are well sealed to ensure its air-tightness, so secular equilibrium between ${ }^{226} \mathrm{Ra}$ and ${ }^{210} \mathrm{~Pb}$ can be reach after 20 days with $95 \%$. In environmental samples measurement, the activity levels are low, so if statistically significant results require long count periods, they are recovery until several days in this work.

\section{Results and discussion}

\subsection{FEP efficiency}

For the analysis of the IAEA-447 standard, a correction factor is generally required for the spectral interfering $\gamma$-rays to determine the net areas of the analytical peaks, because some of those interferences often might contribute to the analytical peaks of 
interest [16]. The nuclide identification was performed using our library containing radioisotopes presented in the IAEA-447 sample where ${ }^{238} \mathrm{U},{ }^{232} \mathrm{Th}$ progenies and ${ }^{40} \mathrm{~K}$ were identified. About ${ }^{234} \mathrm{Th}$ gamma emission at $92.38 \mathrm{keV}$, there is a single peak in the spectral region 92-93 keV resulted from two energies (92.56 keV and $92.78 \mathrm{keV})$, where the total emission probability was taken into account (the net total peak area of this unresolvable multiplet is accounted for without deconvolution).

Table 4 lists the main correction factors for some radionuclides peaks [16].

\begin{tabular}{l|ccc}
\hline Radionuclide & Nuclides in the peak & $\begin{array}{c}\text { Energy } \\
(\mathrm{keV})\end{array}$ & $\begin{array}{c}\text { Proportion in the peak } \\
(\%)\end{array}$ \\
\hline${ }^{234} \mathrm{Th}$ & ${ }^{234} \mathrm{Th}$ & 63.28 & 98.2 \\
\cline { 2 - 4 } & ${ }^{232} \mathrm{Th}$ & 63.81 & 1.8 \\
\hline${ }^{226} \mathrm{Ra}$ & ${ }^{226} \mathrm{Ra}$ & 186.21 & 57.1 \\
\cline { 2 - 4 } & ${ }^{235} \mathrm{U}$ & 185.72 & 42.8 \\
\hline${ }^{212} \mathrm{~Pb}$ & ${ }^{212} \mathrm{~Pb}$ & 238.63 & 62.4 \\
\cline { 2 - 4 } & ${ }^{214} \mathrm{~Pb}$ & 242.00 & 31.7 \\
\cline { 2 - 4 } & ${ }^{224} \mathrm{Ra}$ & 240.99 & 5.9 \\
\hline${ }^{40} \mathrm{~K}$ & ${ }^{40} \mathrm{~K}$ & 1460.82 & 94.8 \\
\cline { 2 - 4 } & ${ }^{228} \mathrm{Ac}$ & 1459.14 & 5.2 \\
\hline
\end{tabular}

Table 4: Interference factors of such radionuclides in IAEA-447 [16].

Table 5 compares the experimental and simulated efficiencies for the IAEA-447 standard for the most intense peak of radionuclides. To calculate the efficiency, we have used the following equation:

$$
\varepsilon=\frac{N_{n e t}}{A(B q) \times I_{\gamma} \times t(s)}
$$

where $A$ is the initial activity carried out with the Darwin software [17] taking into account the radioactive affiliations, $N_{\text {net }}$ is the number of counts under the net peak area, $I_{\gamma}$ is the probability of gamma emission and $t$ the acquisition time.

A number of analytical functions describing the dependence of the FEPE as a function of the energy have been proposed by several authors $[18,19]$. The efficiency function used 


\begin{tabular}{l|ccccc}
\hline Radionuclide & $\begin{array}{c}\text { Energy } \\
(\mathrm{keV})\end{array}$ & $\begin{array}{c}\text { Intensity } \\
(\%)\end{array}$ & $\varepsilon_{\exp }$ & $\varepsilon_{\text {sim }}$ & $\begin{array}{c}\text { Ratio } \\
\left(\varepsilon_{\text {exp }} / \varepsilon_{\text {sim }}\right)\end{array}$ \\
\hline${ }^{210} \mathrm{~Pb}$ & 46.54 & 4.25 & $0.422 \pm 0.006$ & $0.457 \pm 0.001$ & $0.92 \pm 0.01$ \\
\hline${ }^{241} \mathrm{Am}$ & 59.54 & 35.90 & $0.482 \pm 0.060$ & $0.536 \pm 0.044$ & $0.90 \pm 0.23$ \\
\hline${ }^{234} \mathrm{Th}$ & 63.28 & 4.80 & $0.492 \pm 0.040$ & $0.539 \pm 0.068$ & $0.91 \pm 0.22$ \\
\cline { 2 - 6 } & 92.37 & 2.81 & $0.531 \pm 0.02$ & $0.561 \pm 0.067$ & $0.95 \pm 0.16$ \\
\hline${ }^{226} \mathrm{Ra}$ & 186.21 & 3.55 & $0.450 \pm 0.02$ & $0.474 \pm 0.038$ & $0.95 \pm 0.12$ \\
\hline${ }^{212} \mathrm{~Pb}$ & 238.63 & 43.60 & $0.375 \pm 0.005$ & $0.384 \pm 0.069$ & $0.98 \pm 0.19$ \\
\hline${ }^{214} \mathrm{~Pb}$ & 295.22 & 18.5 & $0.294 \pm 0.010$ & $0.311 \pm 0.025$ & $0.95 \pm 0.11$ \\
\cline { 2 - 6 } & 351.93 & 35.6 & $0.253 \pm 0.008$ & $0.263 \pm 0.021$ & $0.96 \pm 0.11$ \\
\hline${ }^{208} \mathrm{Tl}$ & 583.19 & 85.00 & $0.144 \pm 0.007$ & $0.149 \pm 0.025$ & $0.97 \pm 0.22$ \\
\hline${ }^{214} \mathrm{Bi}$ & 609.31 & 45.49 & $0.077 \pm 0.007$ & $0.142 \pm 0.011$ & $0.54 \pm 0.17$ \\
\cline { 2 - 6 } & 1120.29 & 14.90 & $0.039 \pm 0.010$ & $0.071 \pm 0.005$ & $0.55 \pm 0.32$ \\
\hline${ }^{137} \mathrm{Cs}$ & 661.66 & 84.99 & $0.125 \pm 0.001$ & $0.130 \pm 0.004$ & $0.96 \pm 0.04$ \\
\hline${ }^{228} \mathrm{Ac}$ & 911.20 & 25.80 & $0.095 \pm 0.004$ & $0.093 \pm 0.012$ & $1.02 \pm 0.17$ \\
\hline${ }^{40} \mathrm{~K}$ & 1460.82 & 10.60 & $0.053 \pm 0.001$ & $0.052 \pm 0.002$ & $1.02 \pm 0.18$ \\
\hline${ }^{208} \mathrm{Tl}$ & 2614.51 & 99.75 & $0.026 \pm 0.001$ & $0.027 \pm 0.004$ & $0.96 \pm 0.05$ \\
\hline
\end{tabular}

Table 5: Experimental and calculated efficiencies for the IAEA-447 standard.

in this work has the form of logarithmic positive power transferred series, which has been proposed in [20, 21]:

$$
\ln \varepsilon=a_{0}+a_{1} \ln E+a_{2} \ln ^{2} E+a_{3} \ln ^{3} E+a_{4} \ln ^{4} E
$$

Fig. 3 shows the experimental and simulated efficiencies as a function of the energy, where both were fitted using a fourth order polynomial from Eq. 2, because it is the adequate order which groups the best statistical parameters, such as trust and residues factor which must be the smallest in the sense of least squares method.

From Table 5, we can see that the simulated values are always greater than experimental values, excepted for ${ }^{228} \mathrm{Ac}$ at $911.2 \mathrm{keV}$ and for the primordial isotope of potassium ${ }^{40} \mathrm{~K}$ at $1460.82 \mathrm{keV}$, due to the presence of this isotope everywhere and chiefly from the human radioactivity. A good agreement is found to be within $10 \%$ between almost 


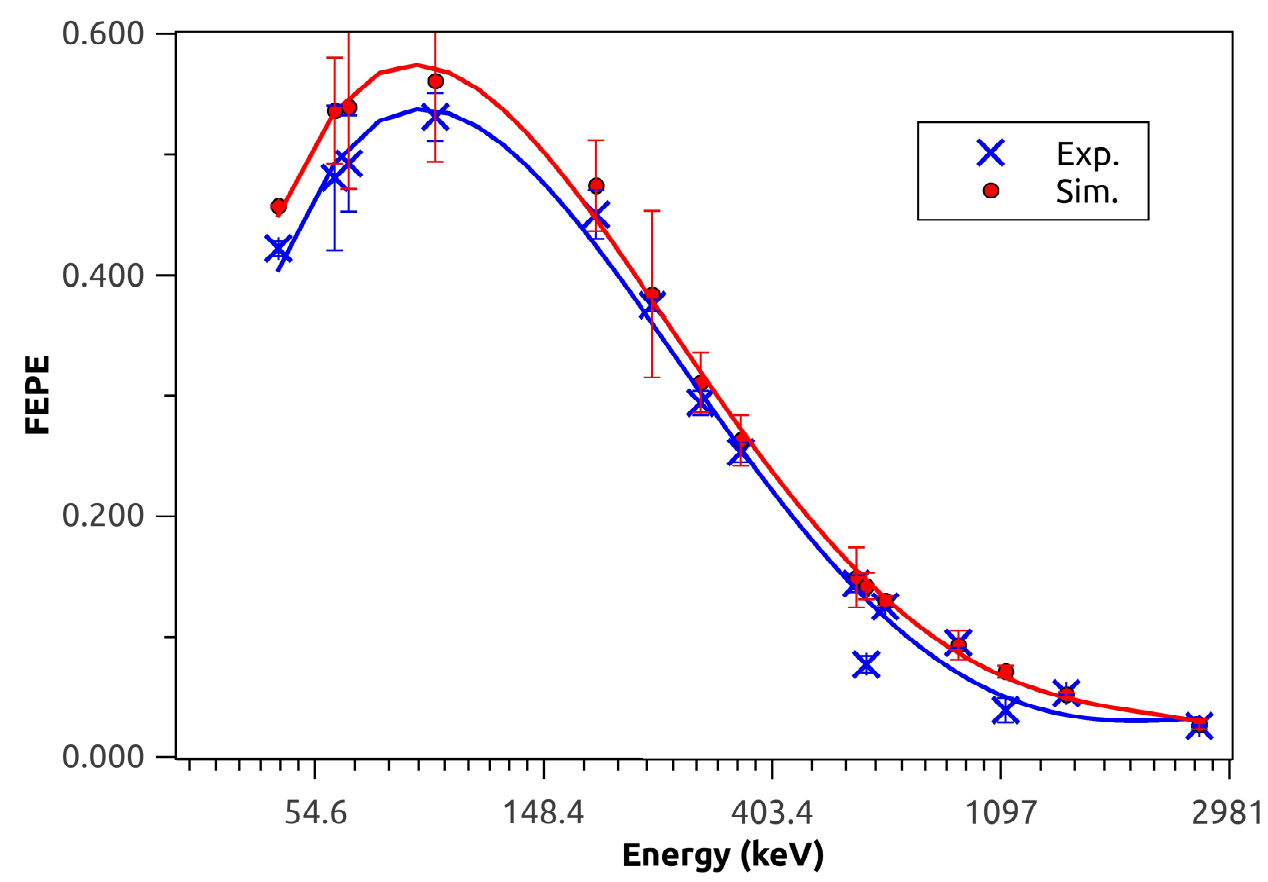

Figure 3: Comparison between experimental and calculated values of the FEP efficiency for the IAEA-447 standard.

all experimental and simulated values as shown in Table 5 and Fig. 3: experimental and simulated efficiencies are very close, starting from $92.37 \mathrm{keV}$ line for ${ }^{234} \mathrm{Th}$ with the ratio $(0.95 \pm 0.16)$. In the low energy range where the self-attenuation phenomenon is not insignificant, a correction in this case should be applied. For some lines with a low number of counts, the uncertainties are important, due to the behaviour of the analysis software towards weak peaks. The most important differences are for ${ }^{214} \mathrm{Bi}$ at the two main lines $609.31 \mathrm{keV}$ and $1120.29 \mathrm{keV}$, where only $54-55 \%$ of counts were detected. In this case, the TCS effect decreases the count number by summing those energies with other in succession.

\subsection{True Coincidence Summing correction}

The true coincidence summing effect was observed for radio-isotopes which have a complex decay scheme, such as ${ }^{214} \mathrm{Bi}$ which can be used in the ${ }^{226} \mathrm{Ra}$ activity evaluation, required in the ${ }^{210} \mathrm{~Pb}$ dating method of lake sediments. For ${ }^{214} \mathrm{Bi}$, we have considered 
height major lines (with the most important intensities) from its numerous $\gamma$ radiations. We assumed that ${ }^{226} \mathrm{Ra}$ is in secular equilibrium with its progenies, which implies that they have the same activity, and we have compared the ${ }^{214} \mathrm{Bi}$ activity with that of ${ }^{214} \mathrm{~Pb}$, which is free from TCS at $351.9 \mathrm{keV}$ and slightly affected with $1.9 \%$ at $295.38 \mathrm{keV}$ [8].

Table 6 shows the TCS correction factors calculated for the major lines of ${ }^{214} \mathrm{Bi}$ in three different ways:

- Activity correction: it was given by the ratio between the raw activity of every line of ${ }^{214} \mathrm{Bi}$ and the activity of ${ }^{214} \mathrm{~Pb}$, used as a reference and equal to $23.85 \pm 0.02$ $\mathrm{Bq} \mathrm{kg}^{-1}$

- TCS factor (Genie 2000): it was determined from the FEPE experimental fitting curve given by Genie 2000;

- Ratio $\varepsilon_{\exp } / \varepsilon_{\text {sim }}$ : that is the ratio between the experimental efficiency and the efficiency calculated from the MCNP6 simulations.

\begin{tabular}{lccccc}
\hline & & & \multicolumn{3}{c}{ Correction factors } \\
\cline { 5 - 6 } $\begin{array}{l}\text { Energy } \\
(\mathrm{keV})\end{array}$ & Intensity & $\begin{array}{c}\text { Activity } \\
(\%)\end{array}$ & $\begin{array}{c}\text { Activity Correction } \\
\left(\mathrm{Bq}_{\mathrm{kg}}{ }^{-1}\right)\end{array}$ & $\begin{array}{c}\text { TCS factor } \\
(\text { Genie } 2000)\end{array}$ & $\begin{array}{c}\text { Ratio } \\
\left(\varepsilon_{\text {exp }} / \varepsilon_{\text {sim }}\right)\end{array}$ \\
\hline 609.31 & 45.49 & $12.72 \pm 0.02$ & 0.53 & 0.58 & 0.54 \\
\hline 1120.29 & 14.91 & $8.91 \pm 0.06$ & 0.37 & 0.57 & 0.55 \\
\hline 1238.1 & 5.83 & $13.05 \pm 0.11$ & 0.55 & 0.56 & 0.55 \\
\hline 1377.7 & 3.97 & $32.07 \pm 0.18$ & 1.34 & 1.40 & 1.27 \\
\hline 1729.5 & 2.84 & $75.07 \pm 0.27$ & 3.14 & 3.07 & 2.78 \\
\hline 1764.5 & 15.31 & $40.70 \pm 0.09$ & 1.70 & 1.75 & 1.61 \\
\hline 1847.42 & 2.11 & $69.94 \pm 0.29$ & 2.93 & 2.15 & 1.76 \\
\hline 2204.1 & 4.91 & $53.99 \pm 0.23$ & 2.26 & 2.38 & 2.20 \\
\hline
\end{tabular}

Table 6: TCS correction factors for the ${ }^{214} \mathrm{Bi}$ major lines.

We can observe an important under estimation at $609.31 \mathrm{keV}$ and $1120.29 \mathrm{keV}$, because these lines are the most involved in the TCS with the other photons emitted by ${ }^{214} \mathrm{Bi}$, leading to an important loss of counts for these peaks. The difference between the 

$\mathrm{keV}$ and $1120.29 \mathrm{keV}$.

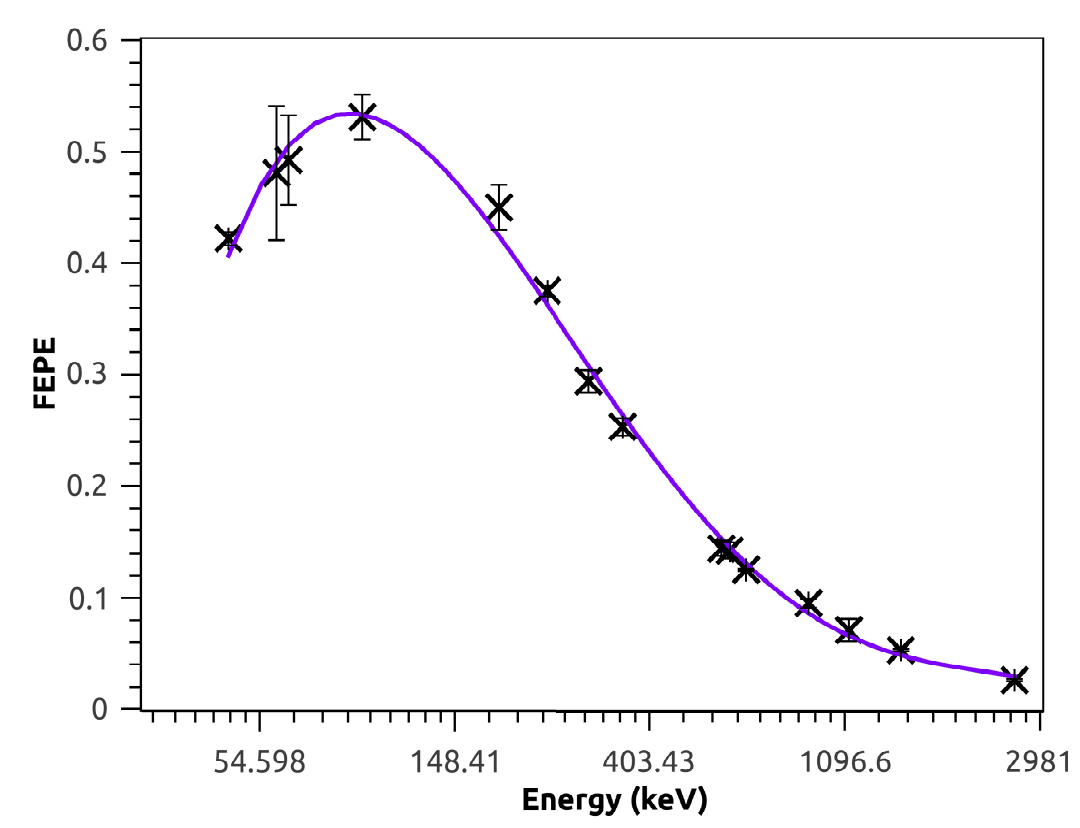

Figure 4: Experimental values of the FEPE for the IAEA-447 corrected from TCS.

correction factor obtained at $1120.29 \mathrm{keV}$ and the TCS factor and the ratio $\varepsilon_{\exp } / \varepsilon_{\operatorname{sim}}$ is due to the weak count rate in this line. The correction factors determined in three different ways are in good agreement and are close to those obtained in the literature for the most of values [8, 22]. For both lines at $1764.5 \mathrm{keV}$ and $2204.1 \mathrm{keV}$, there are significant differences compared with the values from the literature.

Fig. 4 shows the values of efficiency after correction from TCS for ${ }^{214} \mathrm{Bi}$ at 609.31

\subsection{Density effect on TCS}

We have compared the results of efficiencies obtained by IAEA-447, IAEA-RG-U1 and IAEA-RG-Th1 analysis with the common main lines of progenies from ${ }^{238} \mathrm{U}$ and ${ }^{232} \mathrm{Th}$. The results are listed in Table 7 , where efficiency ratios between two standards are shown in the last column with their uncertainties for the same energy lines for the three reference materials. 


\begin{tabular}{l|ccccc}
\hline Radionuclide & $\begin{array}{c}\text { Energy } \\
(\mathrm{keV})\end{array}$ & $\varepsilon_{\text {IAEA }-447}$ & $\varepsilon_{\text {RG-U1 }}$ & $\varepsilon_{\text {RG-Th1 }}$ & $\begin{array}{c}\text { Ratio between } \\
\text { efficiencies }\end{array}$ \\
\hline${ }^{210} \mathrm{~Pb}$ & 46.54 & $0.422 \pm 0.006$ & $0.403 \pm 0.006$ & - & $0.95 \pm 0.01$ \\
\hline${ }^{234} \mathrm{Th}$ & 63.28 & $0.492 \pm 0.040$ & $0.485 \pm 0.007$ & - & $0.99 \pm 0.10$ \\
\cline { 2 - 6 } & 92.37 & $0.531 \pm 0.020$ & $0.518 \pm 0.008$ & - & $0.98 \pm 0.05$ \\
\hline${ }^{226} \mathrm{Ra}$ & 186.21 & $0.450 \pm 0.020$ & $0.425 \pm 0.006$ & - & $0.94 \pm 0.06$ \\
\hline${ }^{212} \mathrm{~Pb}$ & 238.63 & $0.375 \pm 0.005$ & - & $0.369 \pm 0.020$ & $0.98 \pm 0.07$ \\
\hline${ }^{214} \mathrm{~Pb}$ & 295.22 & $0.294 \pm 0.010$ & $0.290 \pm 0.004$ & $0.98 \pm 0.05$ & \\
\cline { 2 - 6 } & 351.93 & $0.253 \pm 0.008$ & $0.241 \pm 0.003$ & - & $0.95 \pm 0.04$ \\
\hline${ }^{208} \mathrm{Tl}$ & 583.19 & $0.144 \pm 0.007$ & - & $0.103 \pm 0.006$ & $0.72 \pm 0.10$ \\
\hline${ }^{214} \mathrm{Bi}$ & 609.31 & $0.077 \pm 0.007$ & $0.062 \pm 0.001$ & - & $0.80 \pm 0.10$ \\
\cline { 2 - 6 } & 1120.29 & $0.039 \pm 0.01$ & $0.03 \pm 0.001$ & - & $0.77 \pm 0.27$ \\
\hline${ }^{228} \mathrm{Ac}$ & 911.2 & $0.095 \pm 0.004$ & - & $0.082 \pm 0.005$ & $0.86 \pm 0.10$ \\
\hline${ }^{208} \mathrm{Tl}$ & 2614.51 & $0.026 \pm 0.001$ & - & $0.014 \pm 0.001$ & $0.54 \pm 0.10$ \\
\hline
\end{tabular}

Table 7: Comparison between IAEA-447, IAEA-RG-U1 and IAEA-RG-Th1 results.

FEPE values of radionuclides presented in the IAEA-447 reference material are always greater than those obtained by IAEA-RG-Th1 and IAEA-RG-U1, because the TCS effect increases with activity where IAEA-RG radionuclides have greater activities than those of IAEA-447. The results show a slight discrepancy between common lines of IAEA reference materials less than $10 \%$ in the range of low energies. This is due to the density difference between IAEA samples, where heavy elements such as thorium and uranium are presented in IAEA-RG, leading to a higher density than IAEA-447. This density impact is presented for all energies. The difference between efficiencies is low for the intermediate energy range. For higher energies, mainly those of ${ }^{214} \mathrm{Bi},{ }^{208} \mathrm{Tl}$, and ${ }^{228} \mathrm{Ac}$, differences are greater and vary between $14 \%$ for $911.2 \mathrm{keV}$ of ${ }^{228} \mathrm{Ac}$ and reach $46 \%$ for ${ }^{208} \mathrm{Tl}$ at $2614.51 \mathrm{keV}$. For such environmental matrices which contain high $\mathrm{Z}$ elements (e.g. thorium, uranium, lead,...) in significant quantities, the threshold at which matrix effects take place is moved to higher energies [23]. 


\subsection{Influence of sample height on the FEP efficiency}

We have further used MCNP6 to compute the FEPE for the IAEA-447 standard as a function of the sample height. The sample heights are 1, 1.5, 2, 2.8 and $3 \mathrm{~cm}$ and the results obtained are shown in Fig 5.a. The impact of the sample height on the efficiency is shown in Fig 5.b for the lowest energies (corresponding to ${ }^{210} \mathrm{~Pb},{ }^{241} \mathrm{Am}$ and ${ }^{234} \mathrm{Th}$ ) and for the highest energies (corresponding to ${ }^{40} \mathrm{~K}$ and ${ }^{208} \mathrm{Tl}$ at $2614.51 \mathrm{keV}$ ).

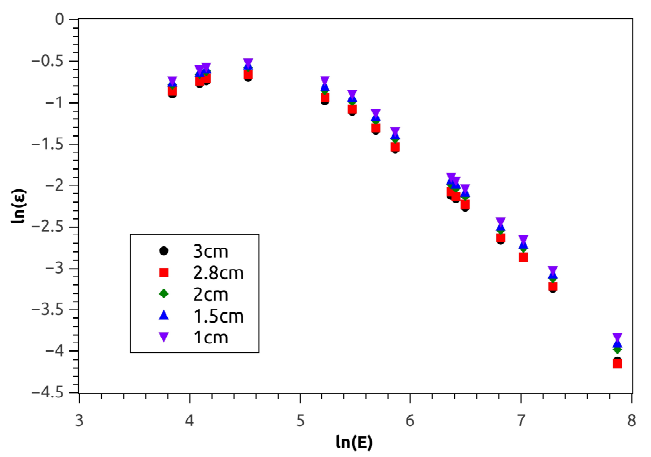

(a) Simulated values of FEP efficiency for several IAEA-447 standard heights.

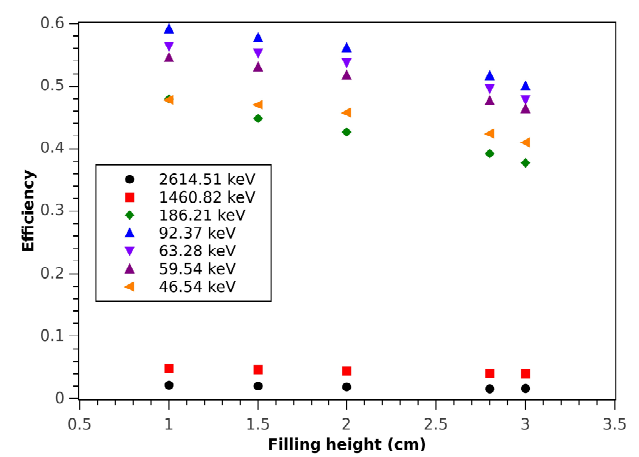

(b) The impact of the IAEA-447 standard heights on FEP efficiency.

Figure 5: Simulated values of FEP efficiency as function of the IAEA-447 standard heights.

The results show that the impact of the sample filling height is very important in the low energy range compared to the high energy range. The efficiency decreases with increasing in the sample filling height. Therefore for our future measurements, we will take into account the height of the sample, through a specific FEPE depending on the filling height.

\section{Conclusion}

The FEPE calibration of an HPGe well-type detector detector was performed in this work motivated by applications in environmental measurements, especially to determine the activities of radioactive fallout in the lake sediments such as ${ }^{210} \mathrm{~Pb},{ }^{241} \mathrm{Am}$ and ${ }^{137} \mathrm{Cs}$, used in dating methods. We have used the IAEA-447 (moss-soil) reference material as a standard to approach at best the matrix effects due to the chemical composition of the samples. A well detector model was implemented in MCNP6 with the features 
provided by the manufacturer. The simulated values are greater than the experimental ones for most of the energy lines. The results show mostly a good agreement with respect to the experimental values and discrepancies are within 10\%. This allows us to determine the efficiency calibration curve without an experimental work, and can be considered as an efficiency transfer model, that can be used in other investigations such as self-attenuation in samples. We have also calculated the true coincidence summing correction factors for the lines emitted in the complex decay chains of ${ }^{214} \mathrm{Bi}$ with three manners, which have showed a good agreement with the literature values. In order to show matrix effects such as the density influence, we have compared the results from the FEPE obtained by three reference materials IAEA-447, IAEA-RG-Th1 and IAEA-RGU1. The impact of the sample filling height was investigated. It was remarkable for low energies, where the efficiency decreases with increasing in filling heights. A reduction of the filling height would diminish the matrix effects [5]. Finally, the efficiency curve can be used in activities evaluation for the environmental measurements, but to improve accuracy, other corrections must be done such as self-attenuation, density and sample height filling effects.

\section{Acknowledgements}

We are grateful to the team of the Laboratoire Souterrain de Modane (IN2P3 UMR 6417) for conducting the measurements on our well detector.

\section{References}

[1] F. Bochud, C.J. Bailat, T. Buchillier, F. Byrde, E. Schmid, J.-P. Laedermann, Nuclear Instruments and Methods in Physics Research A 569 (2006) 790

[2] T. Pilleyre, S. Sanzelle, D. Miallier, J. Fan, F. Courtine, Radiation Measurements 41 (2006) 323.

[3] F. Courtine. Étalonnage d'un spectromètre gamma en vue de la mesure de la radioactivité naturelle. Mesures expérimentales et modélisation par techniques de Monte-Carlo. Ph.D. Thesis, Université Blaise Pascal - Clermont-Ferrand II, 2007 (in French).

[4] F. Courtine, T. Pilleyre, S. Sanzelle, D. Miallier, Nuclear Instruments and Methods in Physics Research A 596 (2008) 229.

[5] S. Dziri, A. Nourredine, A. Sellam, A. Pape, E. Baussan. Applied Radiation and Isotopes 70 (2012) 1144. 
[6] S. Dziri, A. Nachab, A. Nourreddine, A. Sellam, A. Pape, Nuclear Instruments and Methods in Physics Research B 330 (2014) 1.

[7] S. Adekola, J. Colaresi, J. Douwen, W.F. Mueller, K.M. Yocum, Nuclear Instruments and Methods in Physics Research A 784 (2015) 124.

[8] H. Jderstrm, W. F. Mueller, V. Atrashkevich, A.S. Adekola. Nuclear Instruments and Methods in Physics Research A 784 (2015) 264.

[9] D. Degrelle, C. Mavon, J.-E. Groetz, Nuclear Instruments and Methods in Physics Research A 816 (2016) 47.

[10] Y. Morera-Gómez, H.A. Cartas-Aguila, C.M. Alonso-Hernández, C. Nuñez-Duartes, Nuclear Instruments and Methods in Physics Research A 818 (2016) 51.

[11] Genie 2000 3.3, Camberra Industries Inc., September 2013.

[12] D.B. Pelowitz (Ed.), MCNP6 User's Manual, Los Alamos National Laboratory Report LA-CP-1101708, Los Alamos, 2011.

[13] http://www.canberra.com/fr/produits/detectors/germanium-detectors.asp

[14] Shakhashiro, S. Tarjan, A. Ceccatelli, G. Kis-Benedek, M. Betti. Applied Radiation and Isotopes 70 (2012) 1632.

[15] IAEA: https://nucleus.iaea.org/rpst/referenceproducts/referencematerials/

[16] G.R. Gilmore, Practical Gamma-ray Spectrometry, $2^{\text {nd }}$ edition, Nuclear Training Services Ltd Warrington, 2008.

[17] A. Tsilanizara, C.M. Diop, T.D. Huynh, Darwin software SERMA/LEPP/RT/05-3772/A CEA, 2006

[18] K. Debertin, R.G. Helmer, Gamma-and X-ray Spectrometry with Semi- conductor Detectors. Oxford, North-Holland, Amsterdam, 2001.

[19] A. Sanchezreyes, M. Febrian, J. Baro, J. Tejada, Nuclear Instruments and Methods in Physics Research B 28 (1987) 123.

[20] P.W. Gray and A. Ahmad, Nuclear Instruments and Methods in Physics Research A 237 (1985) 577.

[21] M.A Hammed, P.W. Gray, A.H. Naboulsi, T.C. Mac Mahon, Nuclear Instruments and Methods in Physics Research A 334 (1993) 543.

[22] J.-M. Laborie, G. Le Petit, D. Abt, M. Girard, Applied Radiation and Isotopes 53 (2000) 57.

[23] S. Kaminski, A. Jakobi, C. Wilhelm. 2014, Applied Radiation and Isotopes 94 (2014) 306. 